\title{
Experimental Study of Gangue Layer Weakening with Deep-Hole Presplitting Blasting
}

\author{
Jianchi Hao $\mathbb{D}^{1,2}$ Lifeng Ren $\mathbb{D}^{1,2}$ Hu Wen $\mathbb{D}^{1,2}$ and Duo Zhang $\mathbb{D}^{1,2}$ \\ ${ }^{1}$ College of Safety Science and Engineering, Xi'an University of Science and Technology, Xi'an 710054, Shaanxi, China \\ ${ }^{2}$ Ministry of Education Key Laboratory of Western Mine Exploration and Hazard Prevention, \\ Xi'an University of Science and Technology, Xi'an 710054, Shaanxi, China
}

Correspondence should be addressed to Lifeng Ren; lifengrr@126.com and Hu Wen; wenh@xust.edu.cn

Received 21 July 2021; Accepted 16 October 2021; Published 10 November 2021

Academic Editor: Mickael Lallart

Copyright (c) 2021 Jianchi Hao et al. This is an open access article distributed under the Creative Commons Attribution License, which permits unrestricted use, distribution, and reproduction in any medium, provided the original work is properly cited.

\begin{abstract}
Advances in coal mining technology and an increase in coal output are resulting in increasingly challenging conditions being encountered at coal seams. This is particularly so at thin coal seams, where a large number of hard rock layers known as gangue are often present, which seriously affect the normal operation of the shearer and reduce coal output. Therefore, the effective weakening of hard gangue layers in a coal seam is crucial to ensure that the shearer operates effectively and that coal output is maximized. In this paper, the weakening effect of deep-hole presplitting blasting technology on the hard gangue layer in a coal seam is studied via a similar simulation. Four test schemes are designed: (1) A blasting hole spacing of $200 \mathrm{~mm}$ with the holes offset vertically. (2) A blast hole spacing of $300 \mathrm{~mm}$ with the holes offset vertically. (3) A blast hole spacing of $200 \mathrm{~mm}$ with the holes parallel to the gangue layer. (4) A blasting hole spacing of $200 \mathrm{~mm}$ with the holes offset vertically and initiation of interval blasting. The effect of the different blasting hole spacings and arrangements and different detonation methods on the weakening of coal seam clamping by gangue is studied, and the best configuration is identified. This improves the effect of weakening the coal gangue layer by deep-hole presplitting blasting.
\end{abstract}

\section{Introduction}

Intensive coal production is causing mining operations to move to coal seams under increasingly adverse environmental conditions, significantly increasing the difficulty of coal mining $[1,2]$. For example, when mining thin coal seams with hard gangue layers, the hardness of the gangue layer impedes the shearer from cutting normally. Usually, this problem is addressed by weakening the gangue layer of the working surface using traditional blasting techniques. However, sometimes the blasting distance is short, the hole is shallow, and the workload is heavy. Ordinary blasting cannot effectively weaken the gangue layer, resulting in low recovery efficiency at the working face and potential safety risks [3-5]. Therefore, the key to ensuring smooth mining of hard coal seams with thin hard layers is finding a way to safely and efficiently weaken the gangue layer.

Deep-hole presplitting blasting technology, which can be used to enhance the permeability of a coal seam to promote gas extraction [6-12], can also be used to control hard interlayers in the coal seam $[13,14]$. Carrying out this type of blasting in the working face can precrack the gangue in the coal body into small blocks, destroying its integrity and making it looser, and so reduce resistance to the shearer during coal cutting and ensure the smooth progress of mining $[15,16]$. In this paper, deep-hole presplitting blasting is carried out in similar simulation tests that vary the spacing of the blasting holes and the mode of initiation and the blasting parameters are optimized to improve the weakening effect of deep-hole presplitting blasting on coal seam gangue layers.

\section{Test Principles}

Deep-hole presplitting blasting technology makes use of a detonation wave and the high-temperature, high-pressure gas produced by the explosion to cause deformation, 
loosening, and crack formation in coal and rock around the blasting hole [17-20].

Immediately after the explosion, the wall of the blasting hole is instantaneously subjected to high pressure. The pressure then slowly drops. This process involves the following two effects of blasting [21]: the action of stress waves [22-25] and a quasi-static pressure process [26-29].

\subsection{Principles of Simultaneous Blasting at Two Adjacent Holes}

2.1.1. Stress-Enhancement Zone. When detonations are made in two adjacent blasting holes simultaneously, the stress waves released will meet and superimpose between the two holes and additional tensile stress will be generated in the vertical direction, as shown in Figure 1(a), thereby forming a tensile stress-enhancement zone, zone $\mathrm{I}$ in Figure 1(b).

When detonations are made in adjacent holes at the same time, the gas generated by the explosion can keep the two holes in a high-pressure, high-temperature, quasi-static pressure state for a long time. The stress superposition effect will occur everywhere along the line connecting the two holes, leading to the emergence of a stress-enhancement zone. Cracks are more likely to occur in the stress-enhanced area.

2.1.2. Stress-Reduction Zone. As shown in Figure 1(b), with simultaneous detonation at adjacent holes, a second zone between the two holes is affected by the detonation waves. A counteracting phenomenon of radial compressive stress and tangential compressive stress is generated, thus forming a pressure-reduction zone. It can be seen that large blasting products are more likely to be produced in this zone.

\subsection{Principles of Interval Blasting between Two Adjacent} Holes. In interval blasting, blasting hole B in Figure 1(b) acts as a control hole for blasting hole $\mathrm{A}$, increasing the auxiliaryfree surface of the blasting. When the stress wave reaches the free surface, it will be reflected to form a tensile stress wave. When the intensity of the tensile stress wave is greater than the tensile strength of the rock, the Hopkinson effect is produced. At the same time, the reflected waves in the coal body and the stress concentrations at the tip of the crack overlap one another, thereby expanding the range of the fracture zone. At detonation at blasting hole $\mathrm{B}$, the explosion cavity formed by blasting hole A also functions as a control hole [30, 31]. The mechanical model for a control hole is shown in Figure 2.

In Figure 2,

$$
\begin{gathered}
\sigma_{x}=-a^{2} \frac{P_{c}}{L^{2}}, \\
\sigma_{\theta c}=-a^{2} \frac{P_{c}}{L^{2}} .
\end{gathered}
$$

Here, $\sigma_{x}$ denotes the control hole radial stress, $\sigma_{\theta c}$ denotes the control hole tangential stress, $a$ denotes the control hole radius, $P_{C}$ denotes the explosive pressure, $L$ denotes the hole spacing, $r$ denotes the polar radius, and $\theta$ denotes the polar angle.

The tangential stress of the rock mass around the control hole can be expressed by the following formula:

$$
\sigma_{\theta c}=S\left(1+\frac{3 a^{4}}{r^{4}}\right) \cos 2 \theta,
$$

where $S$ is the explosive stress, MPa.

When $r=a$ and $\theta=0, \pi$, the tensile stress value reaches its maximum value. This maximum value occurs at two points, $A$ and $B$, as shown in Figure 2. The maximum value is

$$
\sigma_{\theta c \max }=4 S \text {. }
$$

From the above analysis, it can be seen that tensile stress is at its highest at points A and B on the borehole wall in Figure 2, resulting in the phenomenon of stress concentration. When the tensile strength of the rock mass is less than the tensile stress, initial cracks will occur at points $A$ and $B$ in the coal mass. When the tensile strength of the rock mass is always less than the tensile stress, the cracks will propagate until the tensile strength of the rock mass is greater than the tensile stress.

\section{Similar Simulation Test System}

A similar simulation uses an average coal seam thickness of $1.5 \mathrm{~m}$ on the working face and an average gangue layer thickness of $0.3 \mathrm{~m}$ as a reference. Variation in the stress and strain of the gangue layer during the entire deep-hole presplitting blasting process is analyzed, and the development law of blasting-induced cracks is explored.

A self-built three-dimensional similar simulation testing system, as shown in Figure 3, was used to measure the change in the explosion stress wave during blasting, the strain condition of the gangue layer, and the development of cracks after blasting.

The solid circle at the interface between the coal seam and the gangue layer in Figure 4 shows the position of the blasting hole in the test. The cubes in the gangue layer represent the specific positions where the strain bricks are buried.

The principal strain and principal stress can be calculated with the following formula [32]:

$$
\begin{aligned}
\varepsilon_{12} & =\frac{\varepsilon_{0}+\varepsilon_{90}}{2} \pm \sqrt{\left(\varepsilon_{0}-\varepsilon_{90}\right)^{2}+\left(2 \varepsilon_{45}-\varepsilon_{0}-\varepsilon_{90}\right)^{2}}, \\
\sigma_{12} & =\frac{E}{2}\left[\frac{\varepsilon_{0}+\varepsilon_{90}}{1-\nu} \pm \frac{1}{1+\nu} \sqrt{\left(\varepsilon_{0}-\varepsilon_{90}\right)^{2}+\left(2 \varepsilon_{45}-\varepsilon_{0}-\varepsilon_{90}\right)^{2}}\right] .
\end{aligned}
$$

Here, $\varepsilon_{0}$ is the $0^{\circ}$ strain gauge strain; $\varepsilon_{45}$ is the $45^{\circ}$ strain gauge strain; $\varepsilon_{90}$ is the $90^{\circ}$ strain gauge strain; $E$ is the elastic modulus of the material-the elastic modulus of the similar material used for the gangue layer $=600 \mathrm{MPa}$; and $v$ is Poisson's ratio of the material, $v=0.2$. 


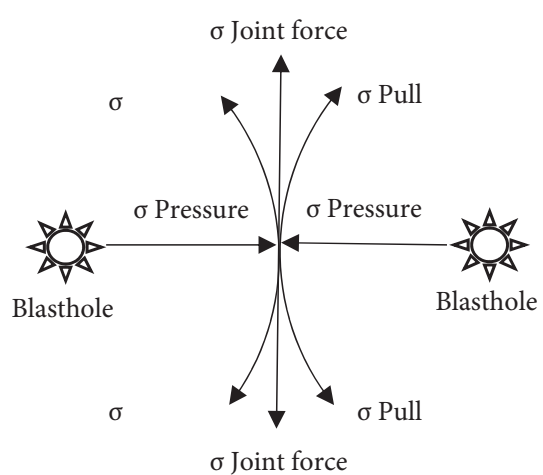

(a)

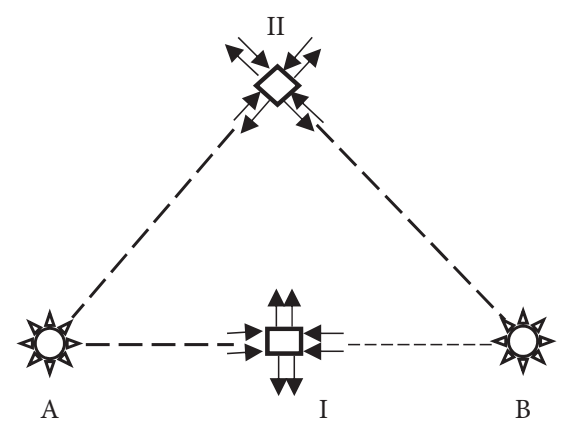

(b)

Figure 1: Stress analysis: (a) stress-enhancement zone and (b) stress-reduction zone.

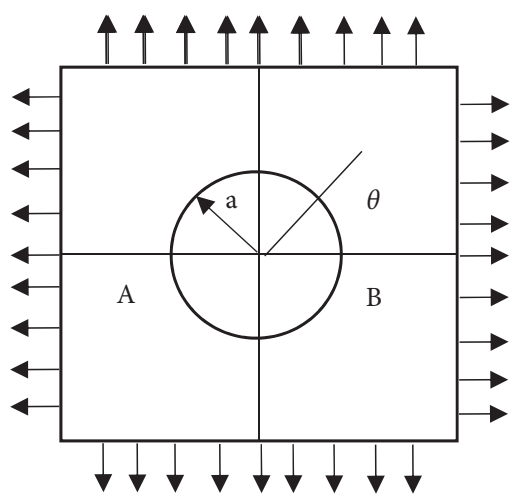

FIgURe 2: Model of control hole mechanics.

\section{Similarity Criteria and Ratios of Similar Materials}

4.1. Similar Criteria. The theoretical basis of similar simulation tests is the similarity principle. Generally, there are two conditions: (1) the existence of geometric similarity, similar motion, similar stress, similar boundary conditions, etc., and (2) a specific proportional relationship between the physical parameters of the similarity model and the simulated object [32-34]. The similarity criteria used in this experiment are as follows:

(1) Geometric similarity:

$$
\alpha_{L}=\frac{L_{p}}{L_{m}}
$$

where $\alpha_{L}$ is the geometric similarity ratio between the prototype and the model; $L_{p}$ is the generalized length of the prototype; and $L_{m}$ is the generalized length of the model.

For this test, geometric similarity ratio between the prototype and the model $\alpha_{L}$ is 10 .

(2) Volume-weight ratio:

$$
\alpha_{\gamma}=\frac{\gamma_{p}}{\gamma_{m}},
$$

where $\alpha_{\gamma}$ is the volume-weight ratio of the prototype to the model; $\gamma_{p}$ is the average density of the prototype rock formation, taken as $2.5 \mathrm{~g} / \mathrm{cm}^{3}$; and $\gamma_{m}$ is the average density of the model material. Generally, $\gamma_{m}$ is suitable for $1.5 \sim 1.8 \mathrm{~g} / \mathrm{cm}^{3}$. $\gamma_{m}=1.5 \mathrm{~g} / \mathrm{cm}^{3}$ is taken in this model.

(3) Similar stress:

$$
\alpha_{\sigma}=\frac{\gamma_{p}}{\gamma_{m}} \alpha_{L}=\alpha_{\gamma} \alpha_{L},
$$

where $\alpha_{\sigma}$ is the stress similarity ratio.

From (7), $\alpha_{\gamma}=2.5 / 1.5=3 / 5$ and $\alpha_{L}=10$. So, $\alpha_{\sigma}=5 / 3 \times 10=16.67$.

Thus, the similarity ratio of the tensile strength $\sigma_{t}$, the compressive strength $\sigma_{c}$, the flexural strength $\sigma_{f}$, the shear strength $\sigma_{s}$, and the elastic modulus $E$ of the material is 16.67 .

4.2. Proportions of Similar Simulated Materials. The distribution of the coal seam, top floor, and lining layer at the onsite working face is used as the reference object of the test to simulate an actual coal-rock mass that is $5 \mathrm{~m}$ long, $5 \mathrm{~m}$ wide, and $6 \mathrm{~m}$ high. The similarity ratio is $1: 10$. In order to make the experiment more realistic, the distribution shown in Figure 5 was adopted for the experiment.

A large number of references were gathered that discuss similar simulated materials and the stress-strain-related parameters of coal and rock masses [35, 36]. Appropriate parameters relating to the coal seam, roof, and bottom plate were determined and are shown in Table 1. Of particular note is that the compressive strength of the sandwiched gangue layer is $6 \mathrm{MPa}$.

\section{Results and Discussion}

5.1. Test Design. In order to improve the gangue layer weakening effect, as well as utilize the stress wave generated by blasting and the expansion of the explosive gas, the blasting holes can be arranged in a vertically staggered manner. The advantage of this arrangement is that the shear stress generated by stress wave superposition is fully utilized and can break up the gangue layer more effectively. Four conditions were tested: 


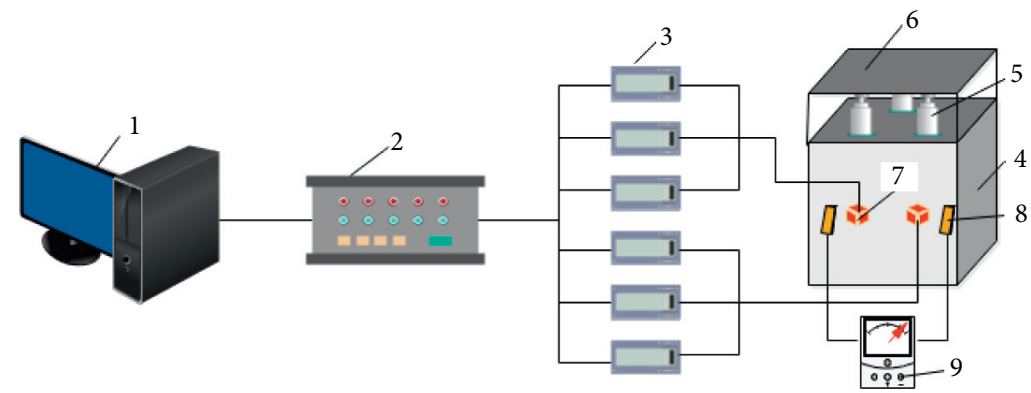

Figure 3: Ultradynamic test system. (1) Computer; (2) super-dynamic strain gauge; (3) sensor; (4) test box; (5) hydraulic jack; (6) steel return plate; (7) strain brick; (8) copper sheet; and (9) ohmmeter.

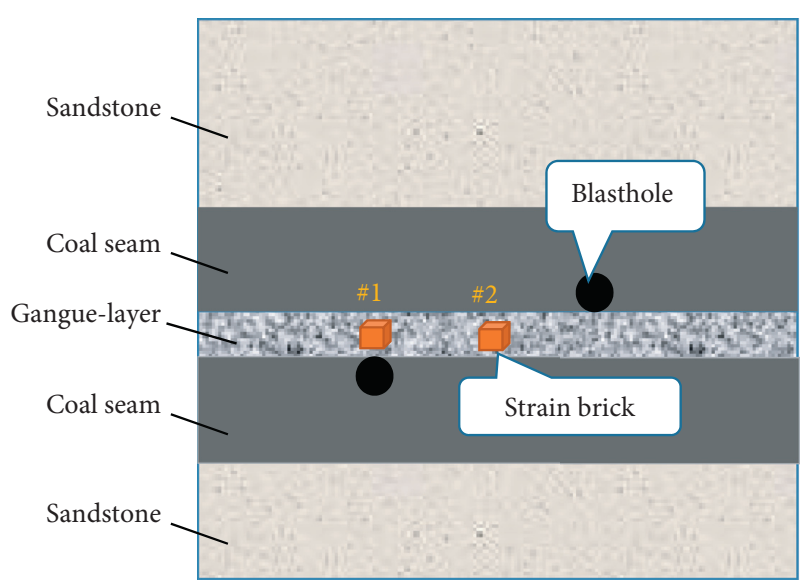

FIgURE 4: Positions of embedded strain bricks.

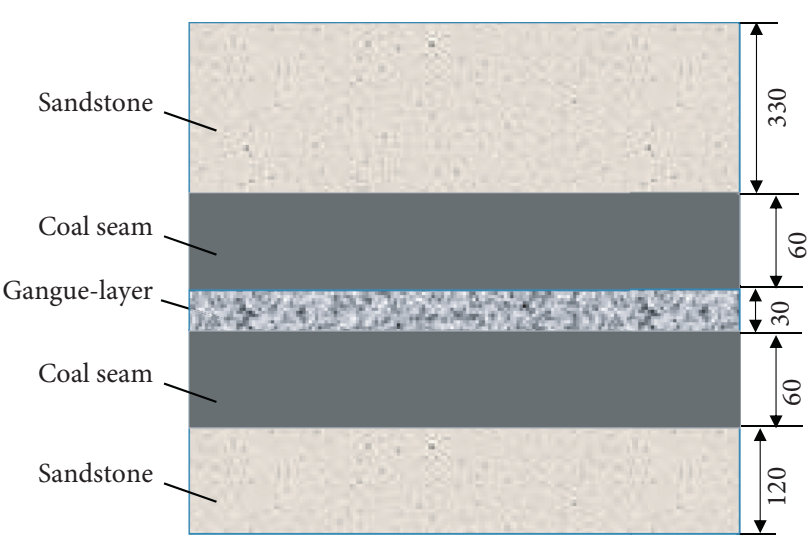

FIGURE 5: Distribution of rock layers in the model.
(1) A blasting hole spacing of $200 \mathrm{~mm}$, staggered upper and lower holes, and simultaneous detonation at the two holes

(2) A blasting hole spacing of $300 \mathrm{~mm}$, staggered upper and lower holes, and simultaneous detonation at the two holes

(3) A blasting hole spacing of $200 \mathrm{~mm}$, the orientation of the line connecting the blasting holes parallel to that of the gangue layer, and simultaneous detonation at the two holes

(4) A blasting hole spacing of $200 \mathrm{~mm}$, staggered upper and lower holes, and initiation of interval blasting at the two holes

\subsection{Test Results}

5.2.1. Test 1. Test 1 includes a hole spacing of $200 \mathrm{~mm}$, vertically offset blasting holes, and simultaneous detonation.

(1) Stress and Strain Analysis. The principal stress and strain curves of the strain bricks were obtained by data processing and are shown in Figure 6.

It can be seen from Figure 6 that the maximum principal stress and strain at strain brick \#1 both occur at around $40 \mu \mathrm{s}$; the maximum principal stress is $11.53 \mathrm{MPa}$, and the maximum principal strain is $0.032 \mathrm{~m}$. These maxima both occur at around $110 \mu \mathrm{s}$ at strain brick \#2; the maximum principal stress is $30.66 \mathrm{MPa}$, and the maximum principal strain is $0.096 \mathrm{~m}$.

Strain brick \# 1 is located in the gangue layer near the blast hole, for which observation and analysis indicate that it is mainly affected by the blast stress wave and the strain produced by fissures around the blasting hole. Strain brick \#2 is located in the center of the line connecting the two adjacent blasting holes. More obvious stress concentration arises here due to the tangential stress caused by the superposition of the stress waves from the two blasting holes. The results show that the maximum principal stresses at both strain bricks are far greater than the $6 \mathrm{MPa}$ compressive strength of the gangue layer and are thus able to play a role in weakening it; the maximum principal strain at strain brick \#2 is about 3 times than that at strain brick \#1.

(2) Resistivity Change Analysis. Changes in the resistance value can be taken as a reflection of the development of cracks through blasting. Before blasting, cracks have not yet developed and the cavity area has not been formed, so conductivity is good. After blasting, a large number of cracks and holes have been formed, so conductivity is poor. The resistance value measured using an ohmmeter was $2.3 \mathrm{M} \Omega$ before blasting and $8.1 \mathrm{M} \Omega$ after blasting. Thus, the resistance value was increased by a substantial amount, $252 \%$, by blasting. This confirms that blasting generated a large number of cracks in the gangue layer. 
TABLE 1: Proximate analyses of the sample.

\begin{tabular}{lcccc}
\hline $\begin{array}{l}\text { Lithology } \\
\text { Thickness } \\
(\mathrm{mm})\end{array}$ & $\begin{array}{c}\text { Compressive strength } \\
(\mathrm{MPa})\end{array}$ & $\begin{array}{c}\text { Average } \\
\text { density } \\
\left(\mathrm{g} / \mathrm{cm}^{3}\right)\end{array}$ & $\begin{array}{c}\text { Similar material ratio (cement: sand: coal powder: lime: } \\
\text { gypsum: water) }\end{array}$ \\
\hline $\begin{array}{l}\text { Roof } \\
\text { sandstone }\end{array}$ & 330 & 3.2 & 1.52 & $0: 7: 0: 0.5: 0.5: 0.8$ \\
$\begin{array}{l}\text { Floor } \\
\text { sandstone }\end{array}$ & 120 & 3.2 & 1.52 & $0: 7: 0: 0.5: 0.5: 0.8$ \\
$\begin{array}{l}\text { Coal seam } \\
\text { Gangue layer }\end{array}$ & 120 & 0.6 & 0.83 & $0: 5: 2: 0.7: 0.3: 0.8$ \\
\hline
\end{tabular}

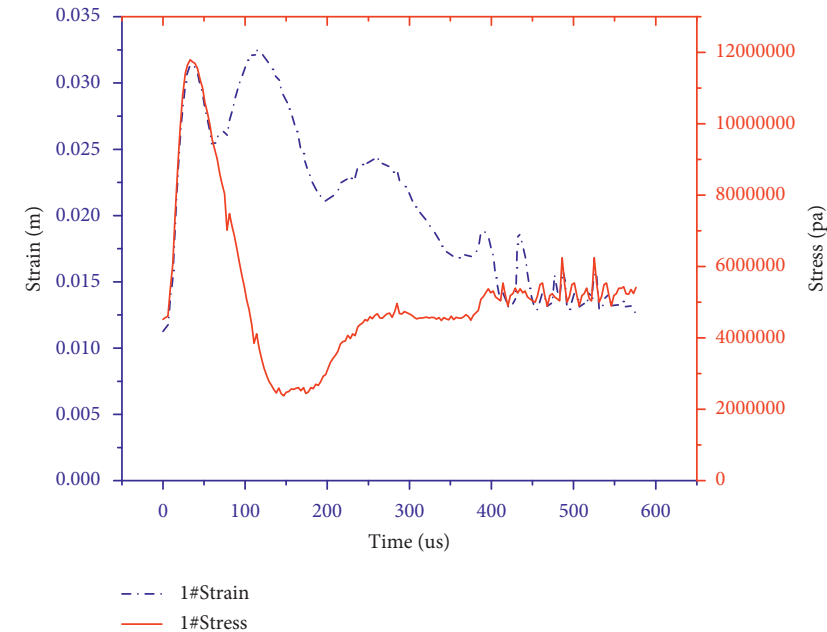

(a)

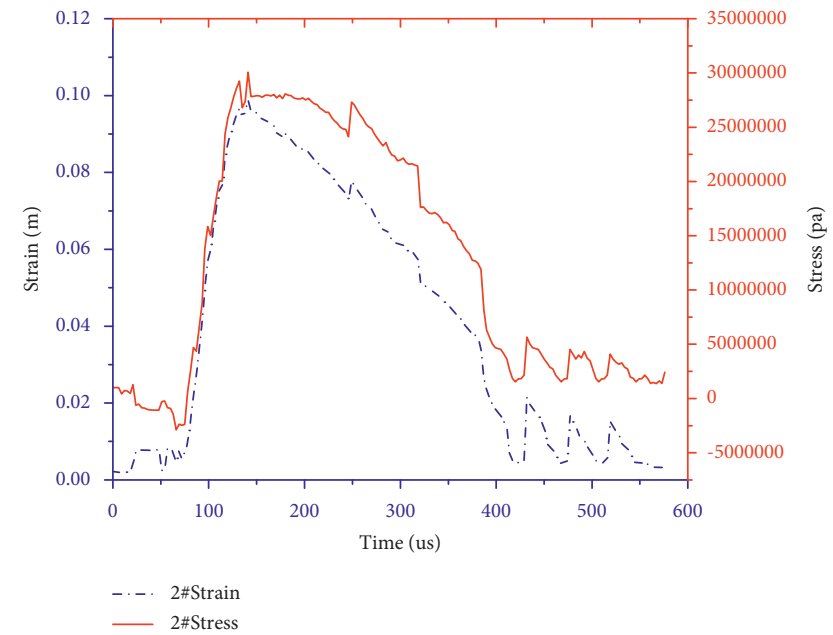

(b)

Figure 6: Test 1 stress and strain curves of (a) strain brick \#1 and (b) strain brick \#2.

(3) Development of Cracks. The coal and rock mass are subjected to a blast shock wave during blasting, and there is clear displacement of the free surface. By removing the upper sandstone and the upper half of the coal seam, we can view the damage and the range of cracks produced during blasting directly. Figure 7 shows that a large number of cracks have formed and developed at the central point between the two blasting holes. In the coal seam within a certain range of the blasting holes, a cavity and a compressed comminution zone are also formed.

5.2.2. Test 2. Test 2 includes a hole spacing of $300 \mathrm{~mm}$, vertically offset blasting holes, and simultaneous detonation.

(1) Stress and Strain Analysis. The principal stress and strain curves under these conditions are shown in Figure 8.

It can be seen from Figure 8 that the maximum principal stress and strain at strain brick \#1 both occur at around $200 \mu \mathrm{s}$; the maximum principal stress is $11.23 \mathrm{MPa}$, and the maximum principal strain is $0.038 \mathrm{~m}$. These maxima appear at around $240 \mu \mathrm{s}$ at strain brick \#2; the maximum principal stress is $27.66 \mathrm{MPa}$, and the maximum principal strain is $0.086 \mathrm{~m}$.

As in test 1, the maximum principal stress at both strain bricks is far greater than the compressive strength of the gangue layer and so it is able to play a role in gangue layer weakening. In addition, there is a higher stress concentration in strain brick \#2, as the maximum principal strain value is about 2 times that in strain brick \#1.

(2) Resistivity Change Analysis. The resistance value was 2.9 $\mathrm{M} \Omega$ before the experiment and $9.5 \mathrm{M} \Omega$ after blasting. This was again a large increase in resistance through blasting, $228 \%$, and it shows that a large number of cracks were produced inside the gangue layer through blasting.

(3) Development of Cracks. It can be seen from Figure 9 that the locus of crack occurrence and development is the central point between the two blasting holes. The displacement of the free surface of blasting is obvious. A cavity and a compressive crushing zone are formed in the coal seam within a certain range of the blasting holes.

5.2.3. Test 3. Test 3 includes a hole spacing of $200 \mathrm{~mm}$, blasting holes arranged parallel to the gangue layer, and simultaneous detonation.

The positions of the blasting holes and of the embedded strain bricks under these conditions are shown in Figure 10.

(1) Stress and Strain Analysis. The principal stress and strain curves of the two strain bricks were obtained through data processing and are shown in Figure 11. 


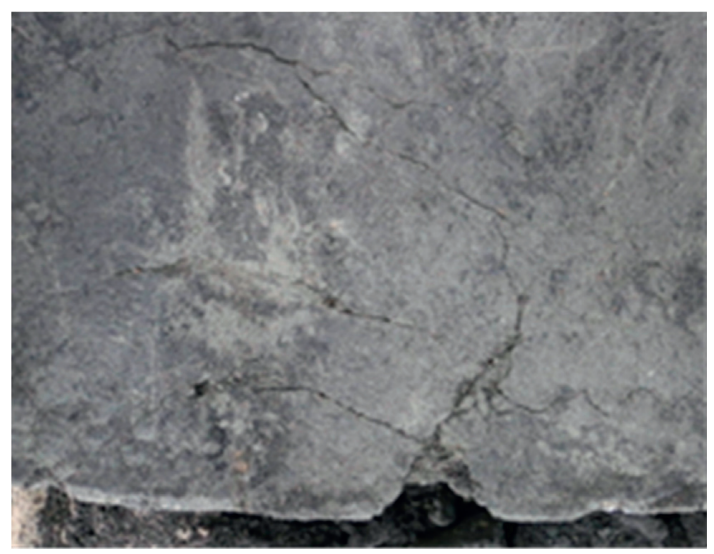

(a)

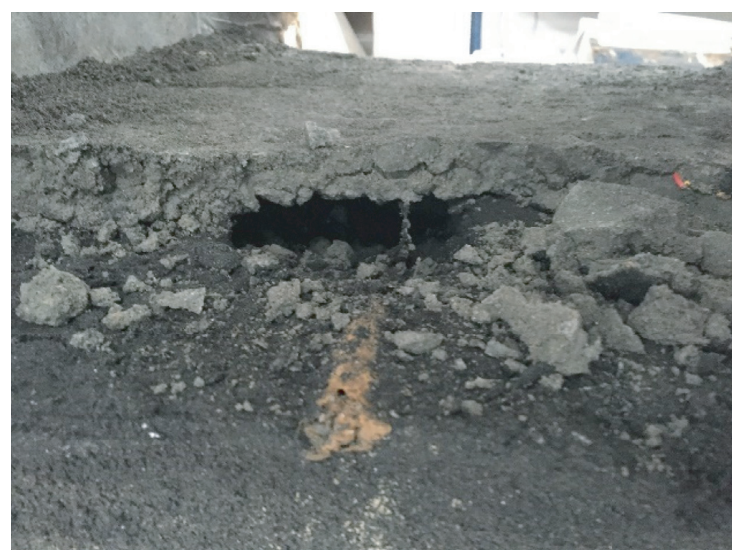

(b)

Figure 7: Test 1 cracks after blasting. (a) Test 1 cracks formed after blasting. (b) Test 1 cavity zone formed after blasting.

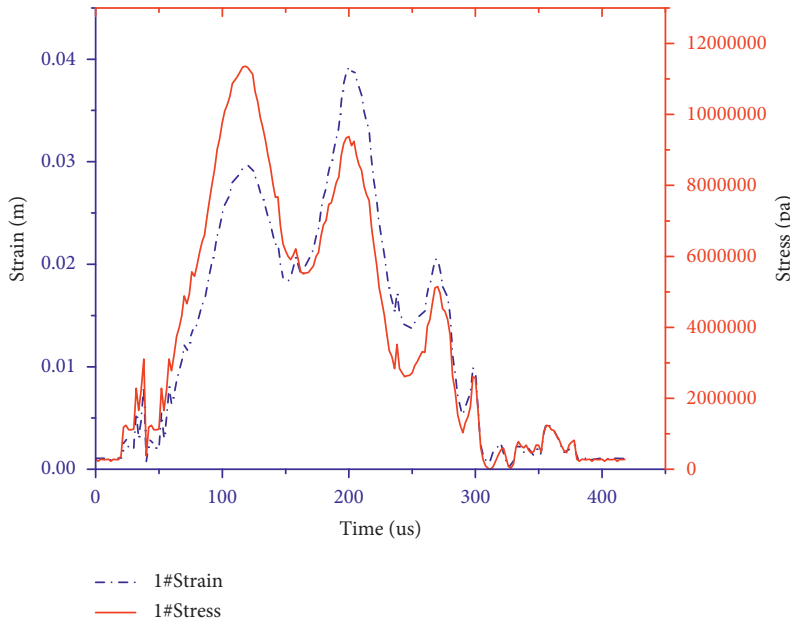

(a)

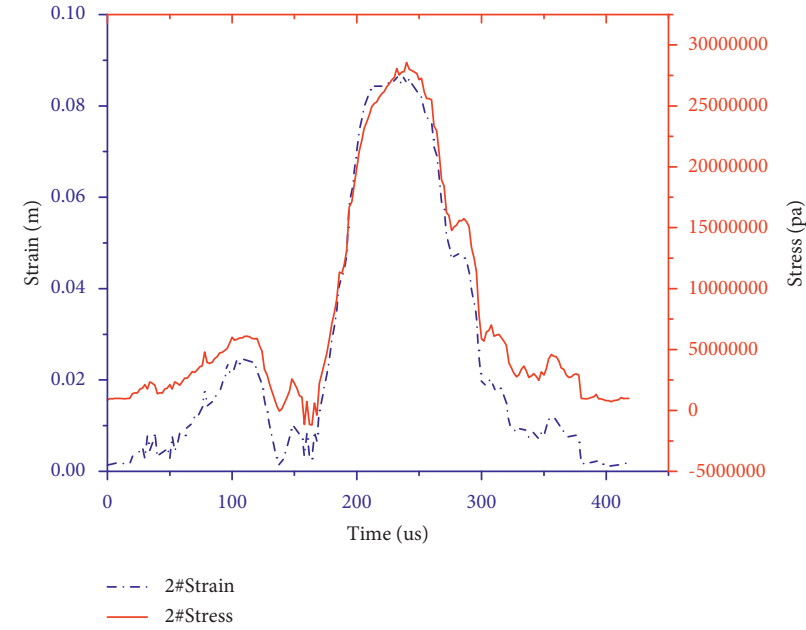

(b)

Figure 8: Test 2 stress and strain curves for (a) strain brick \#1 and (b) strain brick \#2.

It can be seen from Figure 11 that the maximum principal stress and strain at strain brick \#1 both occur at around $75 \mu \mathrm{s}$; the maximum principal stress is $7.93 \mathrm{MPa}$, and the maximum principal strain is $0.016 \mathrm{~m}$. The maximum principal stress and strain occur at around $100 \mu$ s for strain brick \#2; the maximum principal stress is $10.88 \mathrm{MPa}$, and the maximum principal strain is $0.031 \mathrm{~m}$.

The maximum principal stress at both the strain bricks is only slightly higher than the compressive strength of the gangue layer $(6 \mathrm{MPa})$, so little weakening of the gangue layer will be achieved. The maximum principal strain in strain brick \#2 reaches about 2 times than that in strain brick \#1, indicating that it is affected by tangential stress due to the superposition of the stress waves of the two blasting holes, leading to stress concentration.

(2) Resistivity Change Analysis. The resistance value was 3.2 $\mathrm{M} \Omega$ before blasting and 7.1 $\mathrm{M} \Omega$ after blasting, constituting an increase of $122 \%$ in resistivity with blasting. This shows that blasting caused a few cracks to form in the gangue layer.

(3) Development of Cracks. Figure 12 shows that cracks have occurred and developed at the central point between the two blasting holes, but that there are fewer of them than in tests 1 and 2. There is an obvious displacement of the free surface, and a cavity and a compressive crushing zone are formed in the coal seam within a certain range of the blasting holes.

5.2.4. Test 4. Test 4 includes a hole spacing of $200 \mathrm{~mm}$, vertically offset blasting holes, and an interval between detonations.

(1) Stress and Strain Analysis. The principal stress and strain curves under these conditions are shown in Figure 13.

It can be seen from Figure 13 that the maximum principal stress and strain at strain brick \#1 both occur at 


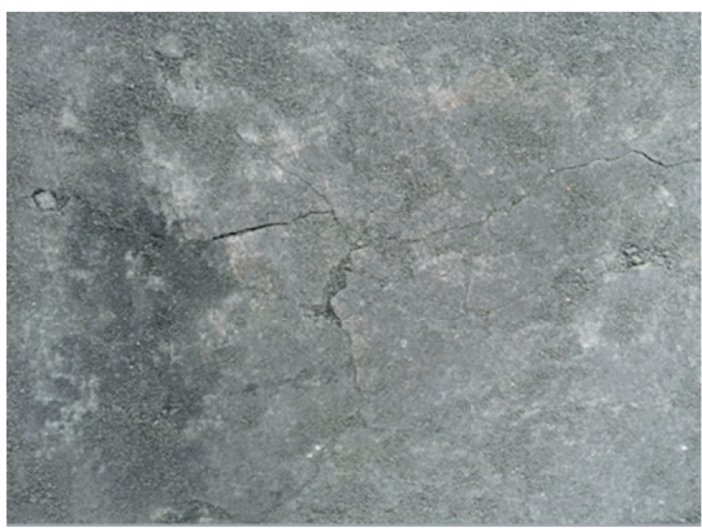

(a)

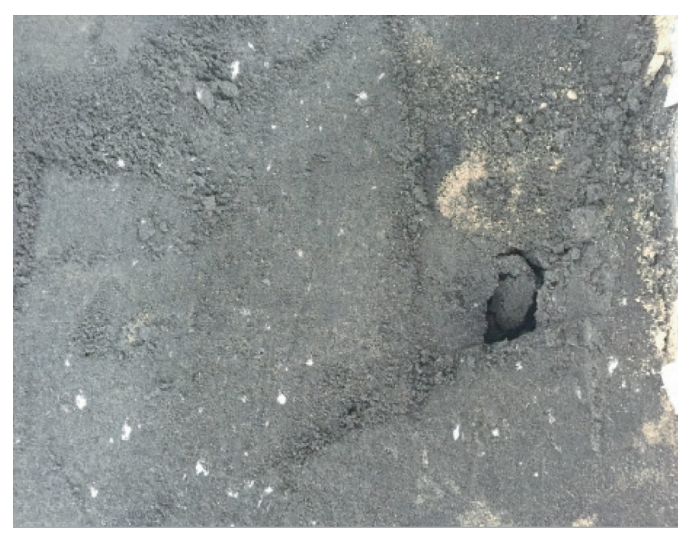

(b)

Figure 9: Test 2 cracks after blasting. (a) Test 2 cracks formed after blasting. (b) Test 2 cavity zone formed after blasting.

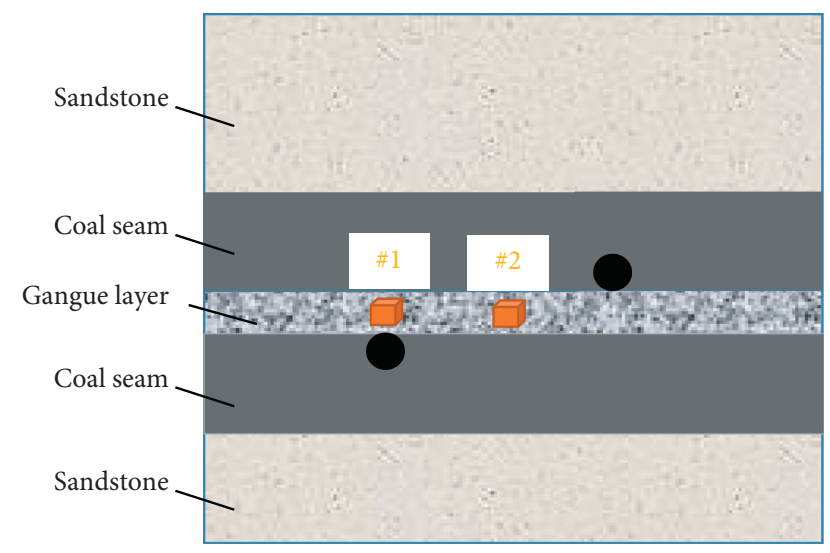

FIGURE 10: Arrangement of blasting holes and of embedded strain bricks for test 3 .

around $220 \mu \mathrm{s}$; the maximum principal stress is $9.83 \mathrm{MPa}$, and the maximum principal strain is $0.037 \mathrm{~m}$. These maxima occur at around $230 \mu$ s for strain brick \#2; the maximum principal stress is $17.88 \mathrm{MPa}$, and the maximum principal strain is $0.022 \mathrm{~m}$.

There is little evidence for stress concentration near strain brick \#2. This is because when interval initiation is used, the gangue layer near strain brick \#2 is not affected by the tangential stress caused by the superposition of the stress waves of the two blasting holes. The maximum principal stress at the two strain bricks is much higher than the $6 \mathrm{MPa}$ compressive strength of the gangue layer, so gangue layer weakening can be achieved. Because there is no stress superposition, the strain value at strain brick \#2 is slightly lower than at strain brick \#1, which is adjacent to a blasting hole.

(2) Resistivity Change Analysis. The resistance value was 2.8 $\mathrm{M} \Omega$ before blasting and $7.8 \mathrm{M} \Omega$ after blasting, an increase of $178 \%$. This shows that a large number of cracks were produced inside the gangue layer through blasting.

(3) Development of Cracks. It can be clearly seen from Figure 14 that cracks were generated and developed along the line connecting the two blast holes and close to the second-detonation blast hole and that cracking is obvious. The blasting-free surface shows a large displacement. A cavity and compression crushing zone have also been formed in the coal seam within a certain range of the blasting hole.

5.3. Comparative Analysis of the Experimental Data. The following conclusions can be drawn from analysis of stress and strain, the change rate of resistance, and crack development in the various similar simulation tests:

(1) When comparing test 1 with test 2 , the test variable is the spacing of the blast holes. The stress wave produced by blasting at two holes overlaps at the midpoint of the line connecting the holes, causing the maximum principal stress and maximum principal strain to be reached at that point and resulting in the formation of a large number of cracks. An increase in the blasting hole spacing results in lower maximum principal stress and maximum principal strain values. Moreover, little change is seen in the maximum principal stress and maximum principal strain generated near a blasting hole, indicating that the adjacent blasting hole has little influence on the effect of blasting near the hole.

(2) A comparison of test 1 and test 3 shows that the maximum principal stress and maximum principal strain are reached at the midpoint of the line connecting the two blasting holes, no matter which hole arrangement is adopted. This is because stress waves are superimposed at that point, resulting in stress concentration. However, because shear stress is generated in test 1 , these maxima are significantly higher than they are in test 3 . It can be seen staggering boreholes achieves a higher degree of weakening of gangue layers than does arranging them in parallel to the gangue bedding. Therefore, a staggered hole arrangement is recommended to achieve maximum weakening of gangue layers in a coal seam. 


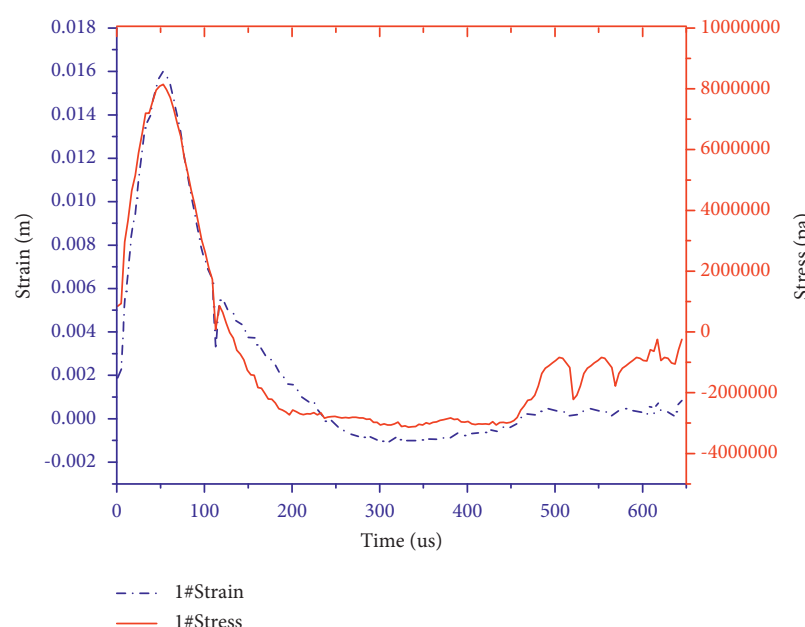

(a)

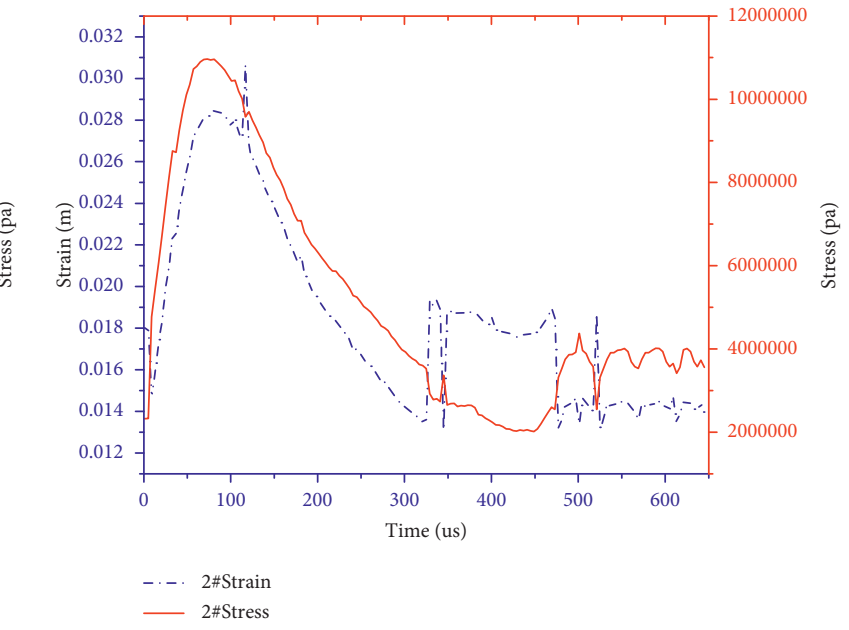

(b)

FIGURE 11: Test 3 stress and strain curves of (a) strain brick \#1 and (b) strain brick \#2.

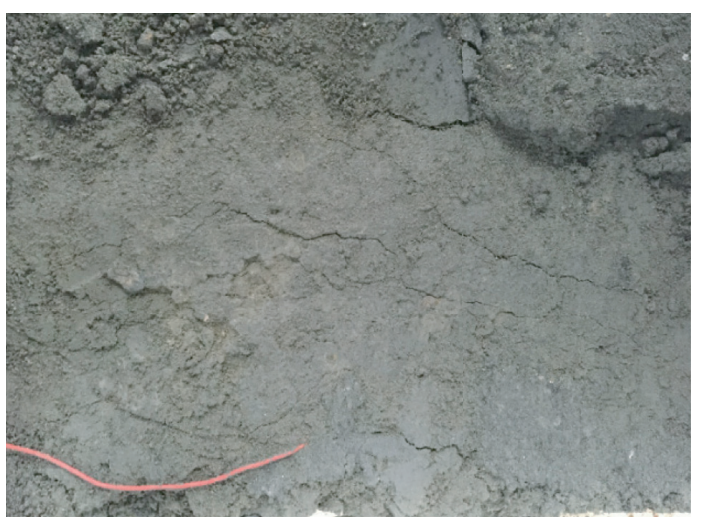

(a)

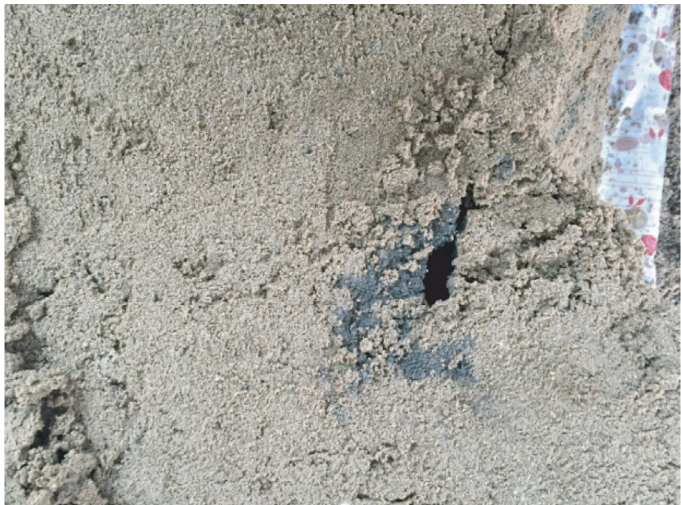

(b)

FIgURE 12: Test 3 cracks after blasting. (a) Test 3 cracks formed after blasting. (b) Test 3 cavity zone formed after blasting.

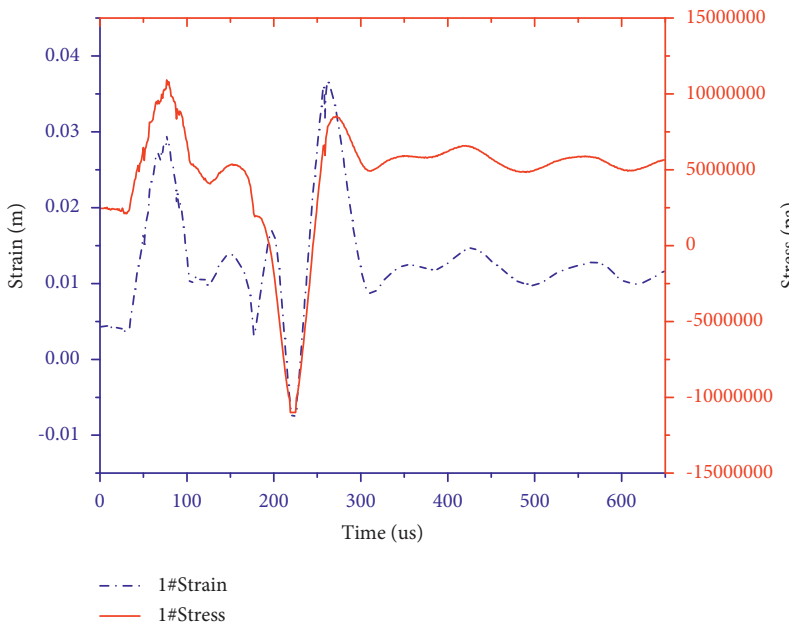

(a)

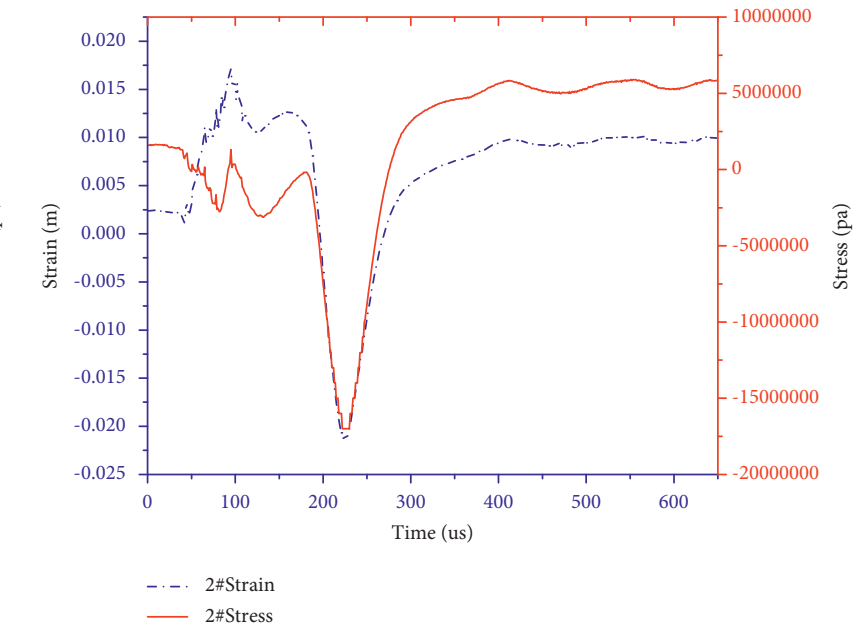

(b)

Figure 13: Test 3 stress and strain curves of (a) strain brick \#1 and (b) strain brick \#2. 


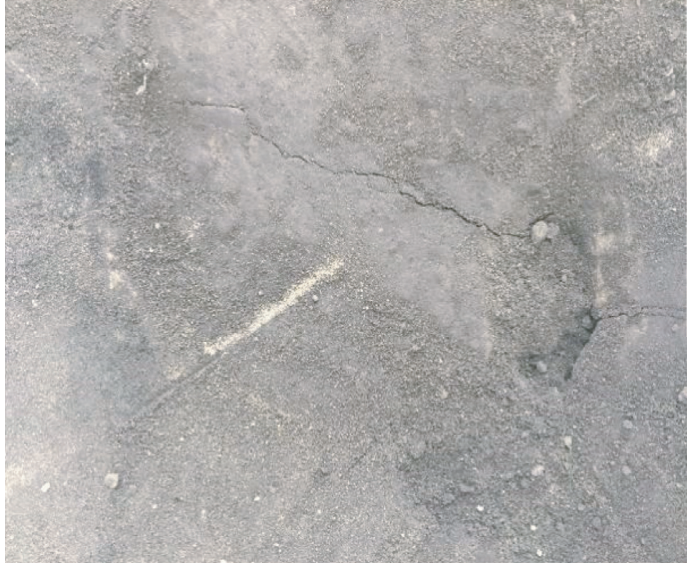

(a)

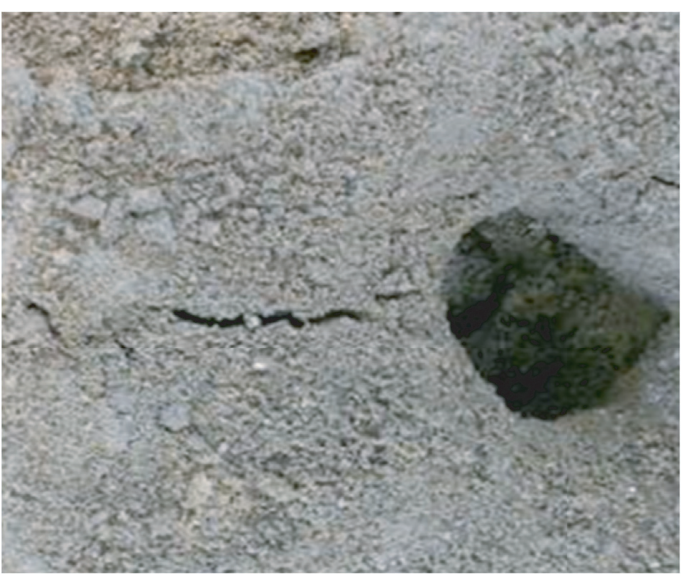

(b)

FIgURE 14: Test 4 cracks after blasting. (a) Test 4 cracks formed after blasting. (b) Test 4 cavity zone formed after blasting.

(3) A comparison of test 1 and test 4 shows that maximum stress and strain are achieved at $130 \mu$ s with simultaneous initiation but slightly later at $220 \mu \mathrm{s}$ with interval initiation. There is no stress concentration with interval initiation, and the maximum stress and strain values are lower than with simultaneous initiation, so simultaneous initiation is more effective for gangue weakening.

(4) In all of the tests, the maximum principal stress was greater than the compressive strength of the ganguecontaining layer, indicating that all four approaches can achieve weakening of a gangue-containing layer.

\section{Conclusion}

Similar simulation tests in which deep-hole presplitting blasting was used to weaken coal gangue have allowed the following conclusions to be drawn:

(1) Maximum principal stress and maximum principal strain decrease with an increase in blasting hole spacing, and the time at which these values are reached increases. Little change, however, is seen in the maximum principal stress and maximum principal strain in the vicinity of the blast hole, which indicates that blasting at adjacent holes has little effect on the blasting hole wall.

(2) When detonation is simultaneous, the stress waves generated by the blasting of the two blasting holes are superimposed at the midpoint of the line connecting the two holes so that the maximum principal stress and maximum principal strain are reached at this point, resulting in the formation of a large number of cracks.

(3) When interval initiation is used, the postinitiation hole and the explosion cavity play a similar role as a control hole, but there is no obvious stress concentration between the two holes.
(4) Theoretical calculation was used to select appropriate parameters for similar simulation testing of deephole presplitting blasting. The effects of blasting under different parameter settings were compared using the method of controlling variables. This comparison shows that while arranging blasting holes in parallel with the gangue layer achieves the desired effect, it can lead to drilling difficulties in the process of weakening the gangue layer. Therefore, it is suggested that a staggered arrangement of boreholes be used as far as possible, as this allows shear stress to be utilized to break up the rocks more efficiently.

\section{Data Availability}

The figures, tables, and models data used to support the findings of this study are included within the article.

\section{Conflicts of Interest}

The authors declare that they have no conflicts of interest.

\section{Acknowledgments}

This work was supported by the National Natural Science Foundation of China (grant number: 51974240 and 52104217).

\section{References}

[1] P. N. Calder and J. N. Tuomi, "Control blasting at sherman mine," in Proceedings of the 6th Annual Conference on "Explosives and Blasting Technique", pp. 312-330, Society of Explosives Engineers, Cleveland, OH, USA, 1980.

[2] F. Cai, Z. G. Liu, and C. Zhang, "Numerical simulation of improving permeability by deep-hole pre-splitting explosion in loose-soft and low permeability coal seam," Journal of China Coal Society, vol. 32, no. 5, pp. 499-503, 2007. 
[3] S.-g. Cao, Y. Li, Y.-b. Liu, L.-q. Zhang, and A.-m. Xu, "Effectiveness analysis of methane-drainage by deep-hole controlled pre-splitting blasting for preventing coal and gas outburst," Journal of Coal Science and Engineering, vol. 15, no. 2, pp. 166-170, 2009.

[4] F. García Bastante, L. Alejano, and J. González-Cao, "Predicting the extent of blast-induced damage in rock masses," International Journal of Rock Mechanics and Mining Sciences, vol. 56, pp. 44-53, 2012.

[5] P. Gong, Y. Chen, Z. Ma, and S. Cheng, "Study on stress relief of hard roof based on presplitting and deep hole blasting," Advances in Civil Engineering, vol. 2020, Article ID 8842818, 12 pages, 2020.

[6] L. Ma, K. Li, D. Xiaohua, and S. Chinyanta, "Research on the effects of blasting vibration attenuation by pre-split crack with HT method," Journal of Computer systems science and engineering, vol. 31, no. 6, pp. 431-438, 2016.

[7] W. B. Guo, H. S. Wang, G. W. Dong, L. Li, and Y. G. Huang, "A case study of effective support working resistance and roof support technology in thick seam fully-mechanized face mining with hard roof conditions," Sustainability, vol. 9, pp. 29-35, 2017.

[8] G. Hu, X. B. Wang, and W. W. Wang, "Study on technology of increasing permeability of low gas permeability coal seam by long-drilling explosion," Journal of Heilongjiang Institute of Science and Technology, vol. 23, no. 2, pp. 159-162, 2013.

[9] P. Konicek, K. Soucek, L. Stas, and R. Singh, "Long-hole distress blasting for rock burst control during deep underground coal mining," International Journal of Rock Mechanics and Mining, vol. 61, pp. 141-153, 2013.

[10] C. J. Konya and A. Konya, "Effect of hole stemming practices on energy efficiency of comminution," Journal of Energy Efficiency in the Minerals Industry, pp. 31-53, 2018.

[11] J. X. Li, B. Q Lin, G. Q. Li, Q. Ye, and S. R. Xu, "The theory and application of loose blasting for increasing permeability and distress in long boreholes," Journal of Coal Mine Safe, vol. 433, pp. 52-54, 2010.

[12] W. Wang, Y. Z. Wei, M. G. Guo, and Y. Z. Li, "Coupling tenology of deep -HolePresplitting blasting and hydraulic fracturing enhance permeability technology in low -permeability and gas outburst coal seam: A case study in the no. 8 mine of Pingdingshan, China," Advances in Civil Engineering, vol. 2021, Article ID 5569678, 12 pages, 2021.

[13] Z. G. Liu, Y. H. Zhang, and Z. A. Huang, "Numerical simulating research on orifice pre-splitting blasting in coal seam," Procedia Engineering, vol. 45, pp. 322-328, 2012.

[14] J. C. Liu, H. T. Wang, Z. G. Yuan, and X. G. Fan, "Experimental study of pre-splitting blasting enhancing pre-drainage rate of low permeability heading face," Procedia Engineering, vol. 26, pp. 818-823, 2011.

[15] J. Liu, Z. G. Liu, J. H. Xu, K. Gao, and W. Zhou, "Application of deep borehole blasting on fully mechanized hard top-coal pre-splitting and gas extraction in the special thick seam," International Journal of Mining Science and Technology, vol. 25, pp. 755-760, 2015.

[16] J. S. Lee, S. K. Ahn, and M. Sagong, "Attenuation of blast vibration in tunneling using a pre-cut discontinuity," Journal of Tunnelling and underground space technology, vol. 52, pp. 30-37, 2016.

[17] Y. Lei, J. J. Liu, S. N. Zhang, W. Zhang, and H. D. Wang, "Contrast test of different permeability improvement technologies for gas-rich low-permeability coal seams," Journal of Natural Gas Science and Engineering, vol. 33, pp. 1282-1290, 2016.
[18] S. X. Cheng, Z. G. Ma, and P. Gong, "Controlling the deformation of a small coal pillar retaining roadway by nonpenetrating directional pre -splitting blasting with a deep hole: a case study in Wangzhuang coal mine," Energies, vol. 13, no. 12, p. 3084, 2020.

[19] X. L. Li, Q. W. Hu, and X. B. Ma, "Experimental research on presplitting blasting of the final highwall of an opencast coal mine," Journal of the Balkan Tribological Association, vol. 22, no. 3, pp. 2857-2869, 2016.

[20] H. C. Sang, Y. Nakamura, and K. Kaneko, "Dynamic fracture process analysis of rock subjected to a stress wave and gas pressurization," International Journal of Rock Mechanics and Mining Sciences, vol. 41, pp. 433-440, 2004.

[21] P. K. Singh, M. P. Roy, and R. K. Paswan, "Controlled blasting for long term stability of pit-walls," International International Journal of Rock Mechanics \& Mining Sciences, vol. 20, no. 70, pp. 388-399, 2014.

[22] Z. J. Sun, J. H. Li, and L. Ding, "Application of long-hole loose blasting in fully-mechanized mining," Shanxi Coal, vol. 12, pp. 55-56, 2011.

[23] Z. L. Wang, X. X. Chen, and S. R. Xing, "Study on stress field distribution characteristics under coal seam pre-splitting blasting," Procedia Engineering, vol. 84, pp. 913-919, 2014.

[24] Q. G. Sun, "Research on status quo and prevention counter measures of coal mine gas disaster in China," Journal of China Coal, vol. 40, no. 3, pp. 116-119, 2014, in Chinese.

[25] A. Thabet and D. Haldane, "Three-dimensional numerical simulation of the behavior of standard concrete test specimens when subjected to impact loading," Journal of Computers and Structures, vol. 79, no. 1, pp. 21-31, 2001.

[26] L. Wojtecki, M. J. Mendecki, W. M. Zuberek, and M. Knopik, "An attempt to determine the seismic moment tensor of tremors induced by distress blasting in a coal seam," International Journal of Rock Mechanics and Mining Sciences, vol. 83, pp. 162-169, 2016.

[27] X. G. Xie, T. Feng, and J. W. Yang, "Monitoring analysis of blasting shock effect motivating coal and gas outburst," Journal of China Coal Society, vol. 35, no. 2, pp. 255-259, 2010.

[28] X. L. Li, Q. W. Hu, X. B. Ma, K. G. Li, and J. Q. Xiao, "Experimental research on presplitting blasting of the final highwall of an opencast coal mine," Journal of the Balkan Tribological Association, vol. 22, no. 3, pp. 2857-2869, 2016.

[29] O. Yilmaz and T. Unlu, "Three-dimensional numerical rock damage analysis under blasting load," Tunnelling and Underground Space Technology incorporating Trenchless Technology Research, vol. 38, pp. 266-278, 2013.

[30] Y. Q. Zhang, H. Hao, and Y. Lu, "Anisotropic dynamic damage and fragmentation of rock materials under explosive loading," International Journal of Engineering Science, vol. 41, no. 9, pp. 917-929, 2003.

[31] P. S. Zhang and S. D. Liu, "Effect of explosive quake in working face on stability of laneway in coal mine," Journal of Mining \& Safety Engineering, vol. 24, no. 2, pp. 208-211, 2007, in Chinese.

[32] J. X. Zhang, B. Y. Li, N. Zhou, and Q. Zhang, "Application of solid backfilling to reduce hard-roof caving and longwall coal face burst potential," International Journal of Rock Mechanics and Mining Sciences, vol. 88, pp. 197-205, 2016.

[33] Z. Y. Zhang, N. Zhang, and H. Shimada, "Optimization of hard roof structure over retained goaf-side gateroad by presplit blasting technology," International Journal of Rock Mechanics \& Mining, vol. 100, pp. 330-337, 2017. 
[34] X. Y. Sun, G. G. Kou, and P. Q. Li, "Experimental study on similarity simulation of overburden movement under repeated mining," Coal Technology, vol. 37, no. 9, 2018.

[35] L. Ren, J. Deng, L. Ma, and J. C. Hao, "Effect of oxygen concentration on the oxidative thermodynamics and spontaneous combustion of pulverized coal," ACS Omega, vol. 6, no. 40 , pp. $26170-26179,2021$.

[36] J. C. Hao, H. Wen, and L. Ma, "Theoretical derivation of a prediction model for $\mathrm{CO}_{2}$ adsorption by coal," ACS Omega, vol. 6, no. 20, pp. 13275-13283, 2021. 